AARP INTERNATIONAL THE JOURNAL

VOLUME $11-2018$ EDITION

AATR

Real Possibilities

\title{
Three Strategies for Establishing AARP as Innovaton Leader
}

By Andy Miller 


\section{Three Strategies for Establishing AARP as Innovation Leader}

By Andy Miller

W hen you think of organizations that are innovation leaders, what names comes to mind? Apple, Facebook, Google and Amazon perhaps? My goal as senior vice president of innovation and product development is to add AARP to this list.

At AARP we know innovative solutions are needed. Right now, 10,000 people turn 65 every single day; by 2035 , one in five people in America will be 65 or older, and one in three households will be headed by someone 65 or older. The Longevity Economy is real, and it's massive, with people over the age of 50 in the US generating $\$ 7.6$ trillion annually in economic activity. It's clear that this demographic, which is often ignored, is a key driver of economic growth.

AARP is challenging outdated beliefs about what it means to age and developing new solutions so we can all choose how we live as we age. Here are three key things AARP is doing now to put us on the innovation map.

Those key areas comprise our roadmap for making AARP an innovation leader. Together, these strategies will help us fulfill our role of being everyday innovators in aging as we connect entrepreneurs with the growing and vibrant market of $50+$ consumers.

\section{Developing New Products}

At AARP we embrace ageless design principles and seek to provide intergenerational solutions that will work for all consumers across generations. We have exciting products that we are pilot testing for launch in 2018. These offerings address our social mission of health, wealth and self.

\section{Collaborating with Industry Leaders}

We are collaborating with foremost industry leaders to drive market solutions. We know that to be the most effective in meeting the needs of people age 50+ we need the assistance of top external players.

Earlier this year AARP's Hatchery - our own innovation lab hosted a qualitative session together with IBM Watson and Local Motors to explore desired features and benefits of an accessible self-driving vehicle (Olli) for $50+$ consumers. This is just one example of the way AARP includes consumer feedback into the innovation process, from the initial brainstorm, to in-person prototyping sessions, to testing of new potential products. 


\section{"Right now, 10,000 people turn 65 every single day; by 2035, one in five people in America will be 65 or older, and one in three households will be headed by someone 65 or older. The Longevity Economy is real, and it's massive, with people over the age of 50 in the US generate $\$ 7.6$ trillion annually in economic activity."}

Another example is AARP's collaboration with Campbell Soup and Pulse@MassChallenge. The purpose of this collaboration is to find startup companies that are integrating technology with nutrition to develop a more personalized health experience with a focus on the $50+$. We're currently judging applicants with new solutions for healthy living. Selected companies will spend time in the AARP Hatchery and at Campbell's headquarters in Camden, New Jersey, working alongside innovation teams from both organizations.

\section{Accelerating Startups}

Through events like TechWeekDC and LivePitch, AARP will continue to engage with companies and entrepreneurs to help them connect

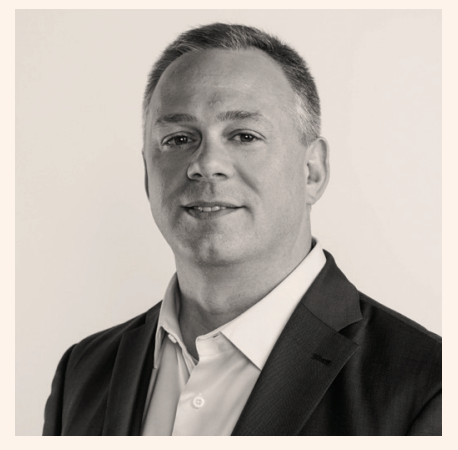

Andy Miller SENIOR VICE PRESIDENT INNOVATION AND PRODUCT DEVELOPMENT, AARP to $50+$ consumers and learn what it is that this audience needs. We also co-create with startups, via collaborations like the one with Pulse@MassChallenge as well as through active engagement with companies like VRHealth, Rendever, and SingFit. 
AARP International engages global stakeholders to spark solutions that strengthen communities, protect the vulnerable and enable people around the world to pursue their goals and dreams. Working with governments, civil society and the private sector, we are focused on enhancing the quality of life for people as they age. We serve as the global voice for AARP, a social change organization with a membership of more than 37 million.

THE JOURNAL ONLINE

aarpinternational.org/journal

AARP INTERNATIONAL ONLINE

aarpinternational.org

FACEBOOK

facebook.com/aarpintl

TWITTER

@aarpintl

CONTACT

AARP International

601 E Street, NW

Washington, DC 20049

United States

T +1 2024342398

E international@aarp.org

AARP International: The Journal is a publication of AARP. The views expressed herein do not necessarily represent policies of AARP and should not be construed as endorsements. The mention of a product or service herein is solely for information to our readers and may not be used for any commercial purpose. AARP, which was established in 1958, is a nonprofit, nonpartisan organization with tens of millions of members ages 50 and older. State offices are located in all 50 states, the District of Columbia, Puerto Rico, and the Virgin Islands.

January 2018

()2018, AARP

Reprinting with permission only. 